\title{
3D cadastre in the Netherlands: Developments and international applicability
}

\author{
Jantien Stoter ${ }^{\mathrm{a}, \mathrm{b}, *}$, Hendrik Ploeger $^{\mathrm{a}}$, Peter van Oosterom ${ }^{\mathrm{a}}$ \\ a OTB, Delft University of Technology, Jaffalaan 9, 2628 BX Delft, The Netherlands \\ ${ }^{\mathrm{b}}$ Kadaster, Hofstraat 110, $7311 \mathrm{KZ}$ Apeldoorn, The Netherlands
}

\section{A R T I C L E I N F O}

\section{Article history:}

Available online $\mathrm{xxxx}$

\section{Keywords:}

3D registration

Land registers

Multi-level property

3D cadastre

\begin{abstract}
A B S T R A C T
This paper presents the design and implementation of the cadastral system extension for registration of 3D rights and restrictions in the Netherlands fitting within the ISO 19152, Land Administration Domain Model (LADM) final draft international standard. The implementation will be conducted in two phases. The first phase of the solution does not require a change of the legal and cadastral frameworks and will be used to gain experience in the challenging domain of 3D cadastre where technical and legal aspects interact. Typical 3D cadastral objects are analysed including their current registration. A procedure to improve the registration is developed that includes an extension of the cadastral system to accept 3D descriptions in 3D pdf format as part of the deed. One of the drawbacks of this solution is that it is not possible to validate the $3 \mathrm{D}$ cadastral representations (Are the volumes closed? Are the neighbours non-overlapping?) The second phase is research in progress and comprises the actual inclusion of the 3D data in the registration, enabling complete validation and even better 3D data management and dissemination. Based on experiences to be collected from the first phase and experiences from other countries, the solution for the second phase will be further refined and subsequently implemented in due time.
\end{abstract}

(c) 2012 Elsevier Ltd. All rights reserved.

\section{Introduction}

Cadastral registration of multi-level property increasingly receives attention because more and more situations occur for which common 2D registration appears to be problematic. Although most legal systems provide the possibility to create property rights with $3 \mathrm{D}$ boundaries, the main registration entity is mostly still a $2 \mathrm{D}$ parcel. Multi-level property situations are therefore projected on the plane and if the consequence is that only part of one (or more) 2D parcel(s) is affected, the ground parcel(s) will be subdivided based on those projections. The current way of registration correctly represents the situation from a legal perspective. Still the registration may be unclear because many small parcels may be necessary to register one single object. This is illustrated in Fig. 1 where a building, appropriately named "The Bridge", is constructed over several other buildings and a public road. The ownership right for the building has been established by a right of superficies on all intersecting surface parcels. To better localise the areas to which these rights apply, specific parcels were generated by the projection of the building, which resulted in a fragmented parcel pattern. Several more examples of unwanted

* Corresponding author at: OTB, Delft University of Technology, Jaffalaan 9, 2628 BX Delft, The Netherlands.

E-mail addresses: jantien.stoter@kadaster.nl, j.e.stoter@tudelft.nl (J. Stoter), h.d.ploeger@tudelft.nl (H. Ploeger), p.j.m.vanoosterom@tudelft.nl (P.van Oosterom). parcel fragmentation are described in Section 4 with more detailed case studies.

The consequence of this way of registration is that the registration is ambiguous and that knowledge of the factual situation might be necessary to understand the registration instead of vice versa. In addition, the registration of a single real world object over several parcels introduces a risk for errors in maintaining the cadastral registers.

Several studies on national and international 3D cadastral developments have been carried out (Aien, Rajabifard, Kalantari, \& Williamson, 2011; Benhamu \& Doytsher, 2003; Döner et al., 2010; Eriksson \& Jonssan, 2010; Guo, Ying, Li, Luo, \& Van Oosterom, 2011; Karki \& McDougall K., 2010; Onsrud, 2003; Paulsson, 2007; Pouliot, T. Fouquet-Asselin, \& Desgroseilliers, 2010; Rahman, Hua, \& Van Oosterom, 2011; Stoter \& Ploeger, 2003; Stoter \& Salzmann, 2003; Stoter \& Van Oosterom, 2005; Stoter \& Van Oosterom, 2006). These studies performed detailed analysis of various complex 3D right configurations and developed several prototypes. Until now these studies focused on studying the optimal legal, technical and cadastral frameworks for 3D cadastre and they proposed several (theoretical) alternatives for proper cadastral registration of multi-level property. However, as concluded in Van Oosterom, Stoter, Ploeger, Thompson, and Karki (2011) hardly any cadastral registration made the step towards a fundamental solution for 3D cadastre. Instead 3D parcels in cadastral maps are (mostly) limited to apartment units, although various countries are 


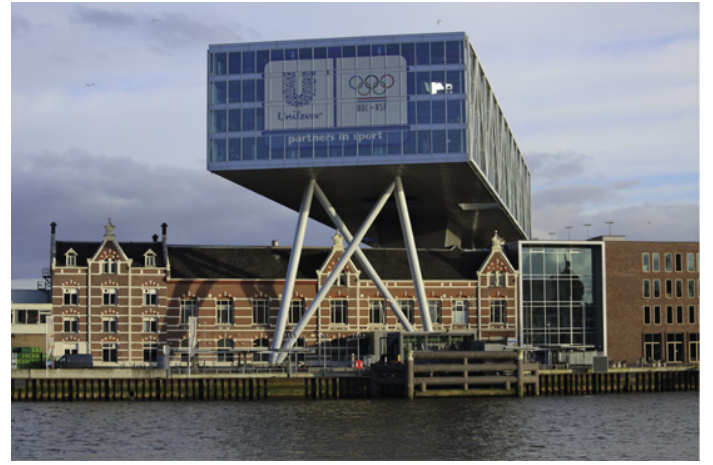

(photo by Frans Schouwenburg, Creative Commons-licence).

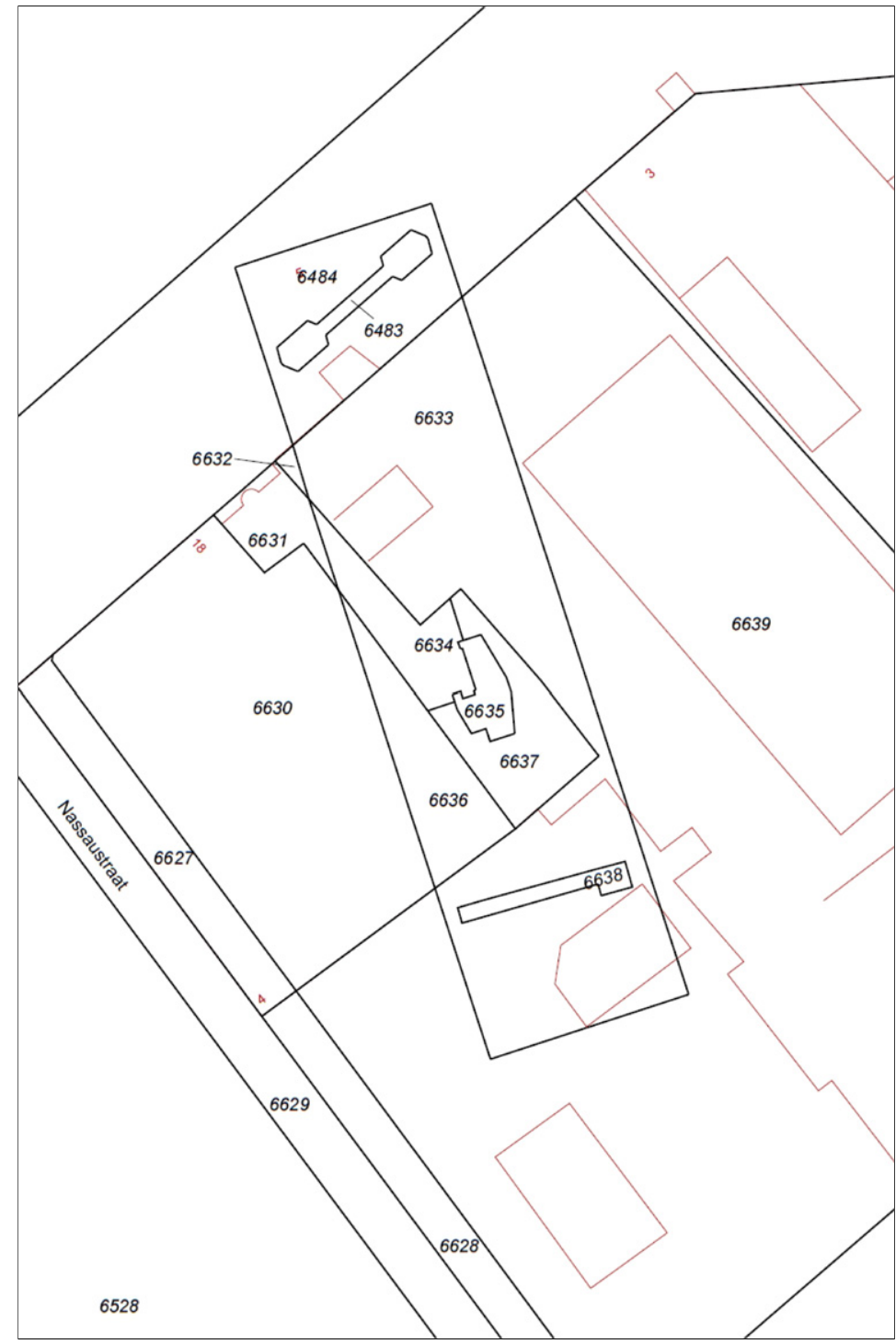

Fig. 1. The bridge ('De Brug') building in Rotterdam above other buildings and roads with the cadastral map of this situation. investigating moving towards 3D registration. An example is the Russian Federation (Vandysheva et al., 2011).

The limited advances in full 3D cadastre implementations throughout the world, might be explained by the fact that the implementation of a 3D cadastre requires close collaboration between legal and technical experts in an empirical environment to understand the impact of each other's domain. The research question of this paper is therefore, how the achieved research results on 3D cadastre can be put into practice. The research of this paper will result in an actual implementation of a 3D registration of multi-level property in the home country of the authors, which is the Netherlands. Also in an international perspective this is an important step forward.

The proposed solution consists of a two-phase process. The first phase fits within the current national cadastral and legal frameworks. The aim of the first phase is to gain experiences and to acquire knowledge by introducing evolving technologies in the legal domain of 3D cadastre. The second phase will build on these experiences and will implement a future-oriented and sustainable solution, also implementing new technologies and allowing a more fundamental change.
The methodology applied in this research consists of several steps and is reflected in the structure of this paper. Section 2 summarises the cadastral alternatives as proposed and studied in our previous research, and that are now part of the ISO LADM (draft) international standard. In Section 3, we analyse the legal aspects of establishing multi-level properties in the Netherlands and how the current cadastral regulations deal with the 3D demarcation of legal units. This work is based on an extensive study of cadastre laws and regulations. Within the legal and cadastral frameworks, the involved parties have a certain amount of freedom to register their multi-level properties. To get more insight into the way this is done in practice, we carried out several case studies. In Section 4 we select three representative cases and report on these. Section 5 proposes the two phases of the implementation of 3D cadastre and presents first results. The paper ends with conclusions and future work in Section 6.

Although this paper proposes a solution for 3D registration within a given legislation, the approach of making 3D registration work within the actual legal framework of Netherlands would apply to other jurisdictions. In addition, we also put the Dutch developments within an international perspective at several locations in 
this paper. Therefore this paper contributes to further reflexions, works and case studies in other countries.

\section{3D cadastre alternatives}

The term '3D cadastre' can be interpreted in many ways ranging from a full 3D cadastre supporting volume parcels, to traditional cadastres in which limited information is maintained on 3D situations. In our previous research (Stoter \& Van Oosterom, 2005, 2006) we have distinguished different conceptual models for a 3D cadastre, which are all included in the ISO FDIS 19152 Land Administration Domain Model (ISO/TC211, 2012; Lemmen, van Oosterom, Thompson, Hespanha, \& Uitermark, 2010) under development within the Technical Committee 211 of the International Organisation for Standardization (ISO). Within the LADM classical cadastral concepts as "parcel" and "boundary" have been extended to include spatial representations of overlapping tenures or claims and also multidimensional objects: 3D and 2D/3D, combined with temporal dimensions (Lemmen et al., 2010). Spatial units may have a $3 \mathrm{D}$ representation, and a provision is made for a mixture of $2 \mathrm{D}$ and 3D spatial units to co-exist. A level is a collection of spatial units with a geometric or thematic coherence. The concept of level is related to the notion of "legal independence" from "Cadastre 2014' (Kaufmann \& Steudler, 1998). This allows for the introduction of spatial data from different sources and accuracies, including utility networks, buildings and other 3D spatial units, such as mining claims, or construction works. New legal topics can simply be added by including a further (information) level. The main class of the spatial units package of LADM is class LA_SpatialUnit (with LA_Parcel as alias). Spatial units are refined into two specializations, which both have quite often a 3D spatial representation (see Fig. 2): 1. building units (in class LA_LegalSpaceBuildingUnit), and 2. utility networks (in class LA_LegalSpaceUtilityNetwork).

The 'Spatial Representation and Survey' subpackage of LADM allows a large number of possible representations of spatial units in 2D, 3D, or mixed (integrated 2D and 3D). All types of LA_SpatialUnit (2D, 3D parcels, buildings, or utility networks) share the same representation structure (Lemmen, van Oosterom, Uitermark, Thompson, \& Hespanha, 2009). An important requirement is that existing 2D data should be easily included. At the same time, the model must support the increasing use of 3D representations of LA_SpatialUnit, without putting additional burden on the simpler $2 \mathrm{D}$ representations. There should be no mismatch between the parts of the domain that are described in 2D and the parts of the domain that are described in 3D. The LADM has been designed using key concepts such as LA_BoundaryFaceString and LA_BoundaryFace. Coordinates themselves are rooted in instances of LA_SourcePoint (mostly after geo-referencing, depending on the data collection method used).

As pointed out by Stoter (2004), in many countries a 2D description should be interpreted as a 3D prismatic volume with no upper and lower bound; see Fig. 3 (upper left and upper right). Using this interpretation, 2D and 3D representations can be unified. The boundaries in the 2D descriptions are called LA_BoundaryFaceString: they use a normal 2D line string for storage, but this implies a series of vertical faces. Theoretically these faces must be completely defined from $+\infty$ to $-\infty$ (or less if restricted by national law). For true 3D descriptions that also have nonvertical faces, the class LA_BoundaryFace is introduced. A liminal spatial unit has a combination of LA_BoundaryFaceString's and vertical LA_BoundaryFace's.

To organise the instances, the LADM has the level model. For example, there can be a base level with ownership LA_SpatialUnit's, which are topologically defined and there could be an additional level with polygon based LA_SpatialUnit's representing servitudes. The concept of levels can be used very well in 3D situations; e.g. level 1 containing ownership (2D, liminal and 3D topological LA_SpatialUnit's) and level 2 would contain ownership of 'legal space' around utilities crossing many other LA_SpatialUnit's (from which the utility network space could be subtracted); (see Fig. 4).

In the LADM, 2D and 3D data are treated in a consistent manner throughout the model. It is important to realise that there is a difference between the 3D physical object itself and the legal space related to this object. The LADM only covers the 'legal space'; that is the space that is relevant for the Land Administration (bounding envelope of the object). This is usually larger than the physical extent of the object itself (for example including a safety zone). To be able to register the (2D or $3 \mathrm{D})$ parcels in the cadastral registration, all real estate objects must have a survey document (LA_SpatialSource), which should make clear to what space the real estate object refers.

\section{Legal and cadastral frameworks for multi-level property in the Netherlands}

The legal and cadastral frameworks for multi-level property in the Netherlands is the starting point for the proposed solutions for $3 \mathrm{D}$ registration and therefore it is important to understand the details of these frameworks. The legal framework sets the rules

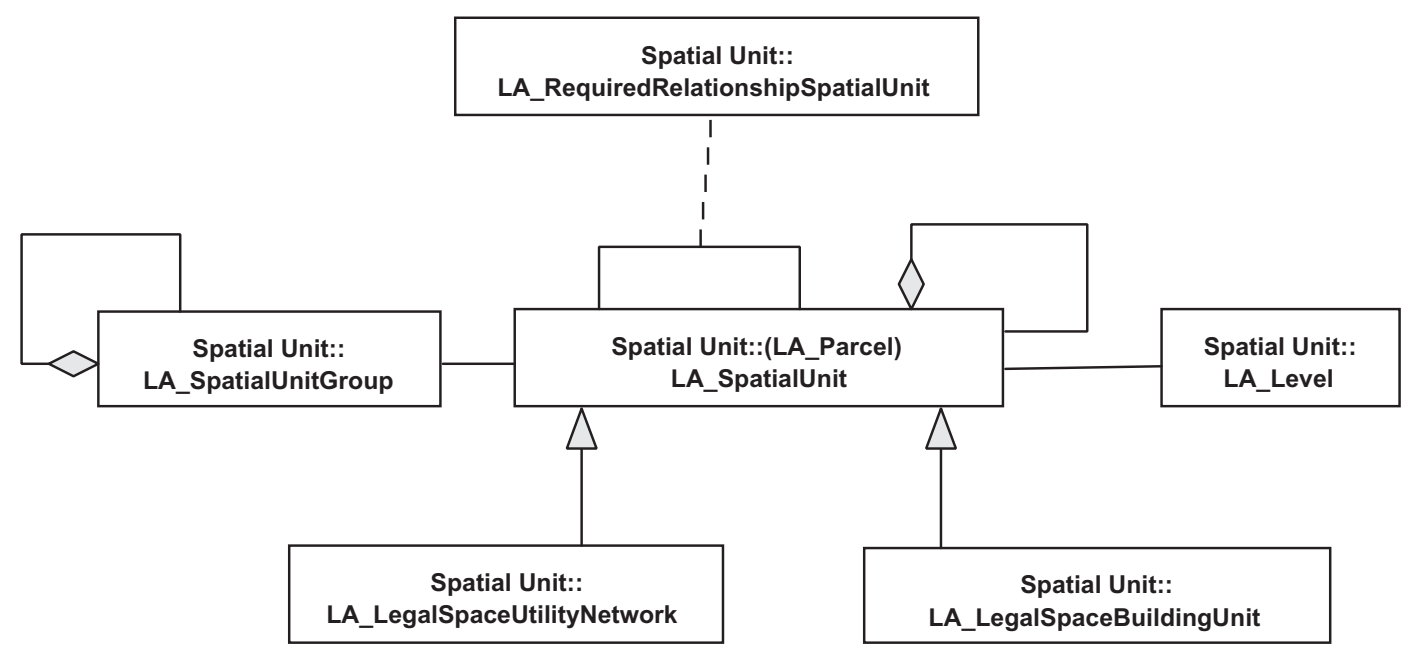

Fig. 2. Classes of spatial unit package and associations between them (ISO FDIS 19152). 

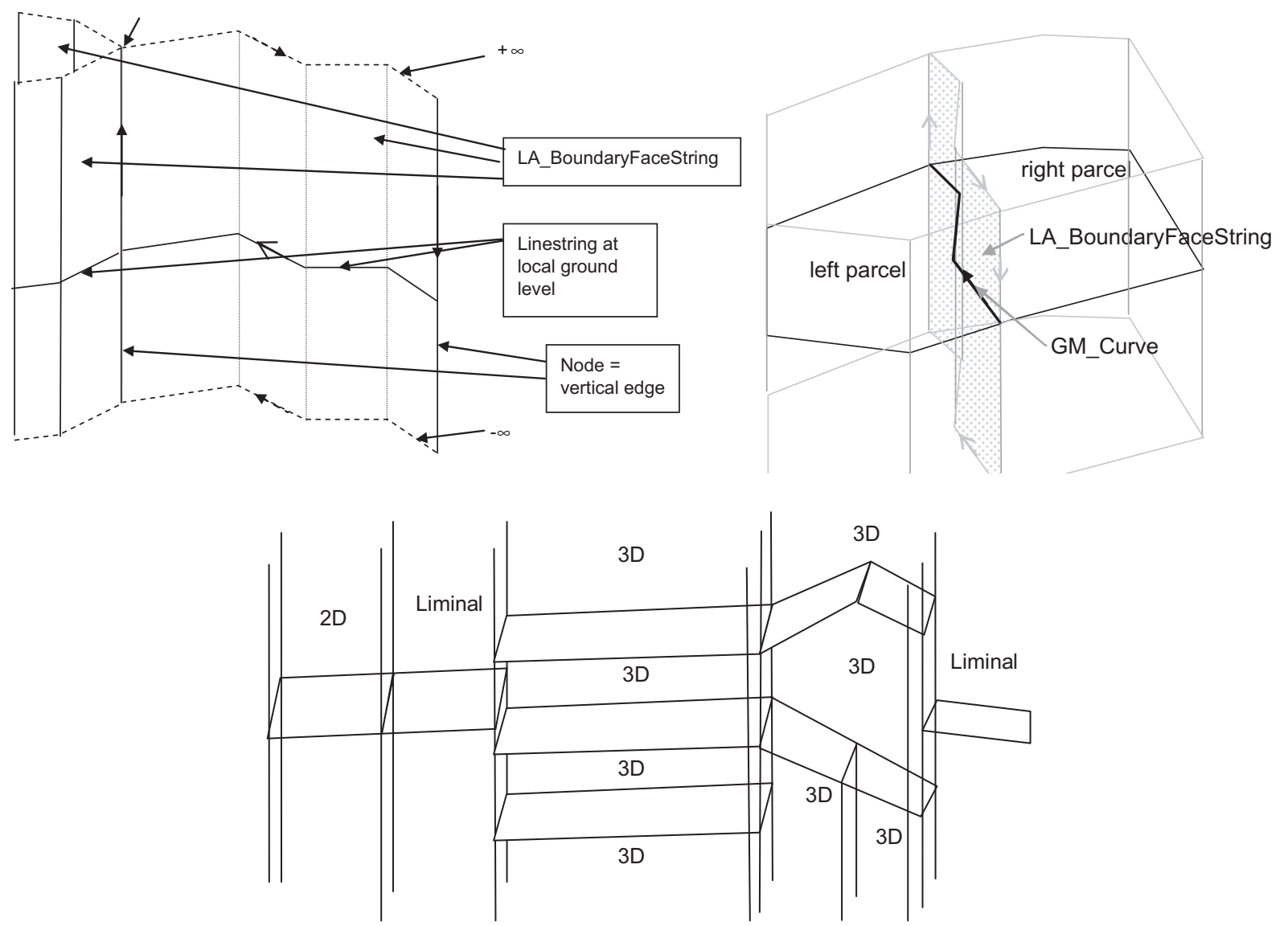

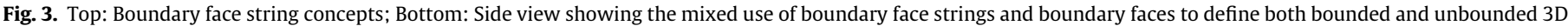
volumes (from ISO FDIS 19152).

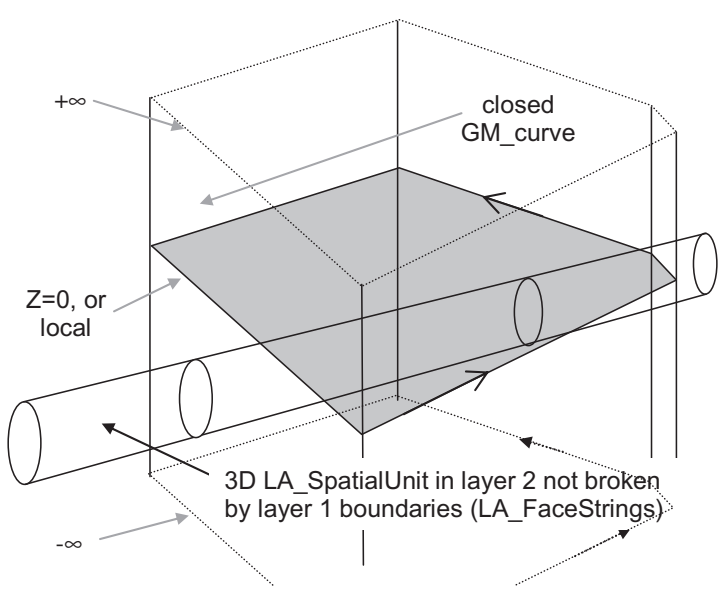

Fig. 4. Multiple levels (note that the ellipses where the level 1 boundaries meet the 3D LA_SpatialUnit in level 2 are there for visualisation support and do not subdivide the object in level 2) (from ISO FDIS 19152).

how property can be divided into the vertical dimensions (Section 3.1). The cadastral framework regulates how such situations can be maintained in an information system and portrayed for the public (Sections 3.2 and 3.3).

\subsection{Establishment of multi-level property}

Like most legal systems, Dutch land law adopts the rule of accession to land taken from Roman law and expressed in the Latin maxim superficies solo cedit (the building becomes part of the land). Therefore ownership of land includes the ownership of buildings and other immovable constructions on and in this land. In addition ownership of land includes the exclusive right to use the subsurface and the air space above the surface. According to Dutch law it is not possible to divide ownership of land as such, e.g. by creating ownership of 3D volumes or the sale of a building without land.

However multi-level property rights can still be created by the land owner via apartment rights (condominium rights) and the establishment of limited rights in rem: superficies, long lease and easement. The latter are rights derived from ownership granting only certain legal powers over land to the titleholder. Furthermore a rule in Dutch land law that puts the superficies rule aside is the so called 'horizontal accession to real estate'. This means that in case a building is constructed on two parcels owned by two different owners the ownership of the building is not divided, but the ownership of the whole building will follow the land on which the main part is constructed.

The most common way to divide the use of building complexes over multiple owners in the Netherlands is to split the complex into apartment rights (condominium rights). According to Dutch law the entire complex (land and building(s)) is in joint ownership. Therefore an apartment right is a share in this joint ownership, while it also provides each apartment owner an exclusive right to use his apartment unit. Furthermore, each apartment owner is compulsory member of the Homeowners Association (Vereniging van Eigenaren). In practice this membership might be an obstacle for selling individual units as well as for their funding. In addition, foreign investors do not always accept the legal concept of joint ownership. Especially, German financiers encounter problems, 
because of the limitations prescribed in their articles of association in the freedom to invest in common ownership.

Alternatives for creation of multi-level property rights are the right of superficies, a right of long lease or an easement. All three are limited rights in rem, that will be established by the land owner. A right of superficies (opstal) is a right to construct buildings or other constructions above, on or in land owned by another person. Interesting is to note that the holder of the limited right of superficies is also the legal owner of the building or construction he is allowed to have on this land. The right of superficies therefore separates the ownership of physical objects or constructions from the land itself. Therefore it is a property right with a clear 3D characteristic. Examples of constructions the right of superficies is established for are underground parkings, road and railway tunnels, pipelines, wind turbines or even technical spaces in buildings. Several of such superficies rights can be established for separate constructions on one and the same parcel.

With a right of long lease (erfpacht) one does not become the legal owner of the real estate, but one gets a right to use it. It should not be confused with the lease in the common law. In Dutch law the right of long lease is a limited right in rem. However, in practise the lessee has a position that is from an economic perspective nearly equal to the position of the land owner. Although in most cases the use applies to the entire property (land with buildings), the right may also be limited in space. An example is the lease of the space above a metro tunnel established for the construction of houses on top of it, or the lease for only the metro tunnel itself.

As will be illustrated by one of the case studies discussed in Section 4 of this paper, the right of superficies and a right of long lease may be established on the same land at the same time to create multi-level properties, such as a right of superficies for the underground parking, and a right of long lease for the office building on top of it, while the land owner retains all the rights on the public space on ground level.

An easement is a burden on the serving parcel in favour of a (usually neighbouring) parcel of another owner (the ruling parcel). Common examples include the right of way, the right to extend a building over the serving parcel or the right to have a pipeline in the serving parcel. But it is also possible that the burden guarantees a free view or prohibits the construction of new buildings. An easement may therefore be used to safeguard the free wind streams for a wind turbine or an unhindered "line-of-sight" for radio-links. In contrast to a right of superficies, the right of easement is thus not necessarily related to physical constructions. Instead a volume of air space can also be controlled by an easement, if the right is defined in terms of "tolerate" or "do not". It is interesting to note that the holder of a right of superficies can also be the beneficiary of an easement. Therefore the right of superficies might be extended on neighbouring parcels by using easements.

Besides the above rights, the registration of ownership of cableand pipeline-networks (compulsory since 2007) results in a separation of property in the vertical dimension. This is described in detail in Stoter and Ploeger (2003) and Döner et al. (2011). Because of its very specific nature this ownership and its registration in the cadastre will not be discussed further in our paper.

The choice whether to use apartment rights, right of superficies, right of long lease or an easement to establish multi-level property is up to the involved parties, who will often follow the advice of their legal advisers, such as a notary.

\subsection{Land administration in the Netherlands in a nutshell}

The Dutch system of land administration is based on the deeds registration as introduced in the beginning of the 19th century. One organisation, the Netherlands Cadastre and Land Registry
Agency maintains both the land registers (register of deeds) and the cadastre (cadastral registration and cadastral map). Security of title is provided by the close cooperation between the Latin notariat and the land registrar. Transfer of rights in land requires the registration of a notarial deed in the land registers. Both the right and the object of the right (in general a piece of land) must be identified in the deed.

\subsection{Publication of $3 D$ property relationships in the land administration}

For describing 3D boundaries of properties, requirements only exist for deeds that establish apartments rights. The law requires the registration of a separate plan per floor in the land registers. These floor plans provide a general overview of the land and building(s), and show the boundaries of the individual apartment units. However, this is not always a clear reflection of the multi-level property situation. In the case of a large building complex it may require a challenging mental exercise to reconstruct the complete ownership situation on the basis of a large number of (large) floor plans, as in Fig. 5. This Figure shows a drawing that is added to a deed of division, registered in the land administration.

This is especially true if the apartment units are situated at different levels and for units with disconnected parts (for example a unit on the second floor with a storage in the cellar or a maisonette). The cadastral map itself shows only the ground parcels of the apartment complex and (in an additional layer, and only for purposes of reference) the footprint of the building. Note that the footprint is defined as the intersection of the 3D object with the earth surface (not to be confused with the projection of the 3D object onto the earth surface). Currently the Dutch Kadaster is working on an improved digital access to the floor plans in the land registers. It is expected that in 2013 it will be possible to access digital (scanned) apartment drawings directly from the cadastral registration. Despite the increased accessibility, this still requires to mentally integrate individual drawings to understand the entire ownership (as intended in the 3D reality).

In the case of the description of the spatial (i.e. 3D) dimensions of a right of superficies, the right of long lease or an easement right, Dutch law does not provide any requirements, except the general principle laid down in the Civil Code that the property should be "identifiable".

However for 2D demarcation of limited rights, a rule in the cadastral legislation and regulations does exist. That is, when a limited right only applies to part of a parcel, normally the exact $2 \mathrm{D}$ boundaries of the right will be surveyed and a new parcel is created at the exact location of the limited right. The consequence can be fragmented parcel creation as will be seen in case studies in Section 4. It should be observed that in case of a difference of the geometry in cadastral maps and the description of the boundaries in the deed, the latter will be decisive.

In practice both sketches and more detailed drawings can be registered in the land registers to show the 3D extent of limited rights or restrictions. The land registrar accepts detailed 3D representations for a better reflection of the legal situation, but (s)he cannot demand this. The format of the 3D representation can be horizontal and/or vertical cross section(s), but also a digital 3D pdf (Adobe, 2012), since this fits within the currently used ELAN (i.e. electronic conveyance) system (Kadaster, 2007). The Netherlands was the first country in the world supporting $100 \%$ electronic conveyancing with this system.

Despite the possibility to register a 3D representation, in practice a reference to a "demarcated area at location" is sufficient. This of course has its risks because the real world at this location can change. In case the deed provides no description of the boundaries at all, the land registrar will refuse the registration of the deed. Within this wide frame of possibilities (between 3D representation 


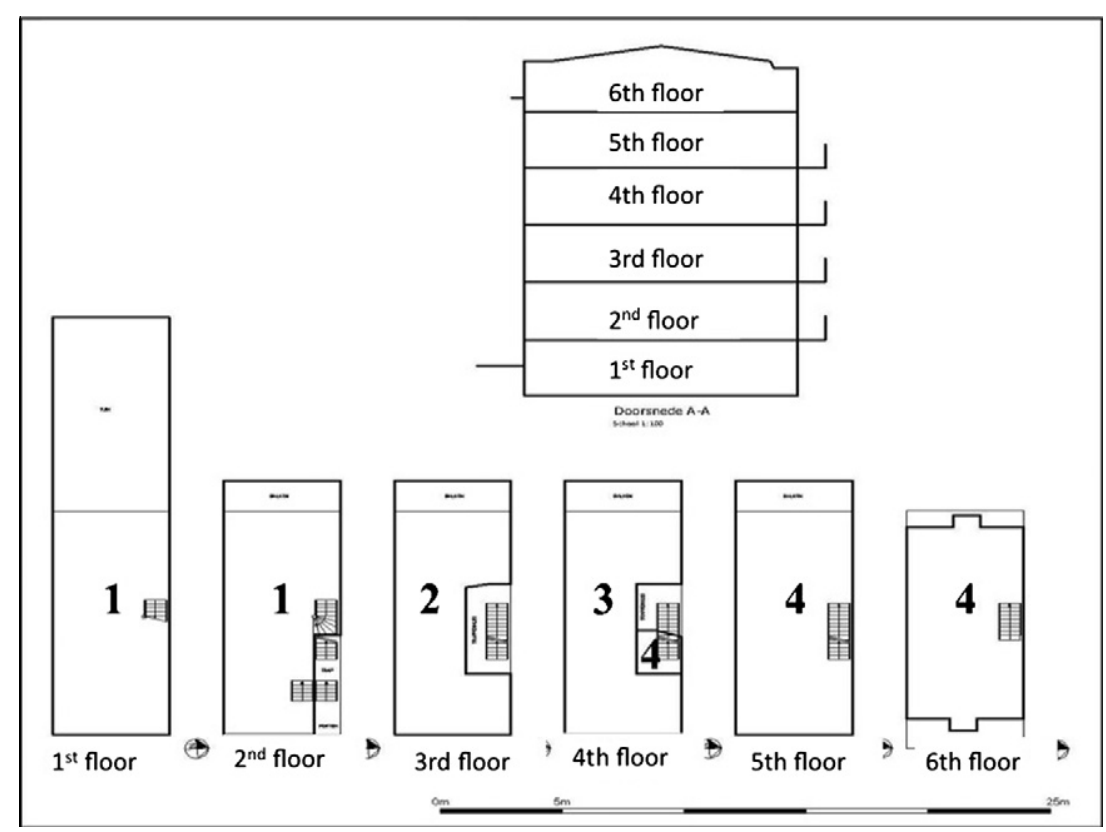

Fig. 5. Floor plans added to a deed of division of a rather simple building complex.

and vague indication) the choice of description as well as the legal value of the description is currently left to the parties (read: the notary who draws up the deed).

Because reliable and observable reference points are often missing, in practice the intentions of the involved parties are only verbally described in the deed. Consequently a 3D representation added to the deed often acts as a sketch with no legal meaning with respect to the exact locations of the boundary. In theory, the deed can include a representation of (surveyed) boundaries, which are considered legally binding if the parties declare that the boundaries exactly reflect their intentions. In practice this rarely happens, although it is obvious that it would be helpful for both the submitting and the receiving parties if some voluntary best-practice based guidelines would exist; e.g. to clarify the situation in the form of $3 \mathrm{D}$ representation.

\section{Case studies}

This section evaluates current practice of 3D registration with three case studies, which were selected as representative 3D cadastre cases from many multi-level property cases that we studied: a building above a road (i.e. bridge-building); a building-complex above an underground parking place that is registered through its foundation piles; and a building-complex registered on many parcels, that were generated because of objects above and below the surface.

\subsection{Case 1: bridge-building over a highway}

The first case is the bridge building in The Hague over the A12 highway (Fig. 6).

A study of the public and cadastral registers shows that the building owner has a perpetual right of long lease on the footprints of the building. This building owner is also owner of the part of the building that was built over the A12 via a right of superficies. In the deed that establishes this right, the space of the right has been specified by indicating per floor the location where the right applies to (in layered 2D) (see Fig. 7). Specific for this case is that those floor plans added to the deed do not match the cadastral map at that location (compare Figs. 6right and 7): the area of the right of superficies overlaps the parcels in the map on which a right of long lease has been established, i.e. specific very small parcels have been created at the location where the building touches the ground). Apparently, the two processes (one for registration in the land registers and one for surveying the cadastral parcels) operated independently. In this situation, the deed will prevail above the cadastral map, which was updated at a later moment.

\subsection{Case 2: office tower and underground parking at the Amsterdam Zuid-as}

The second case of a multi-level property situation is the division of property between a building (an office tower) and the underground parking at the Amsterdam Zuid-as (Fig. 8; right building). The foundation piles of the office tower are situated in the underground parking. For both constructions leaseholds have been established by the land owner, the municipality of Amsterdam. As land owner the municipality retains all rights on the public space on the roof of the parking that is not occupied by the office tower; as near the entrance of the building (shown in Fig. 8).

The lease right on the office tower on top of the parking is registered through its foundation piles resulting in about 80 mini-parcels in Fig. 9. Actually the foundation piles of the office tower run through the underground parking itself (from the roof to the floor of the parking). Therefore the multi-level properties created here are of a rather complex nature, i.e. the footprint of the foundation piles are used and not the footprint of the building (the building stands on the ground).

Consequently - as the authors experienced themselves - the multi-level properties can only be understood properly after visiting the site itself. The registration is even made more complicated since the office tower in its turn is divided into apartment units.

Apart from the resulting non-transparent property registration, this "footprint" way of registration leads to inefficient parcel creation, which are hard to maintain. The obscurity of those mini-parcels is even bigger in case of rights for two distinct objects above and below the parcel, such as a building-over-road combined with underground constructions (as will shown in case 3). It may well happen that in a deed referring to the mini-parcels a typing error 

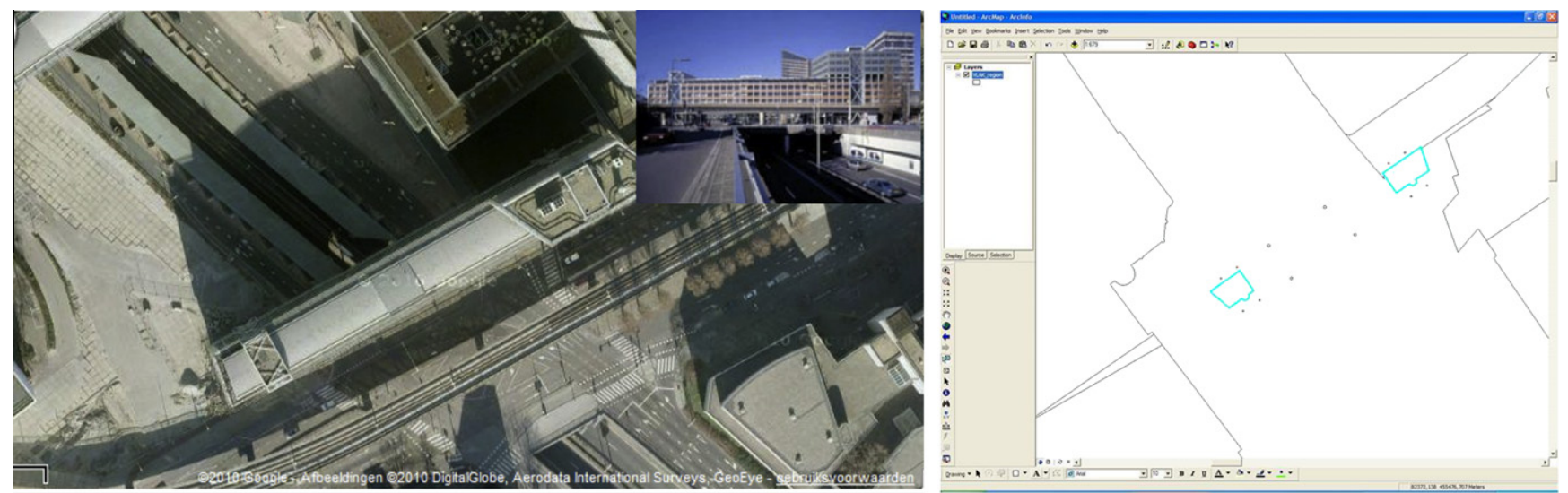

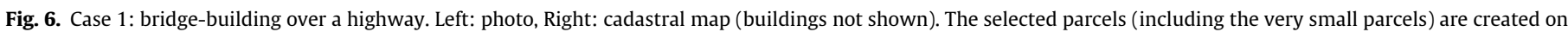
the location where the building touches the ground.
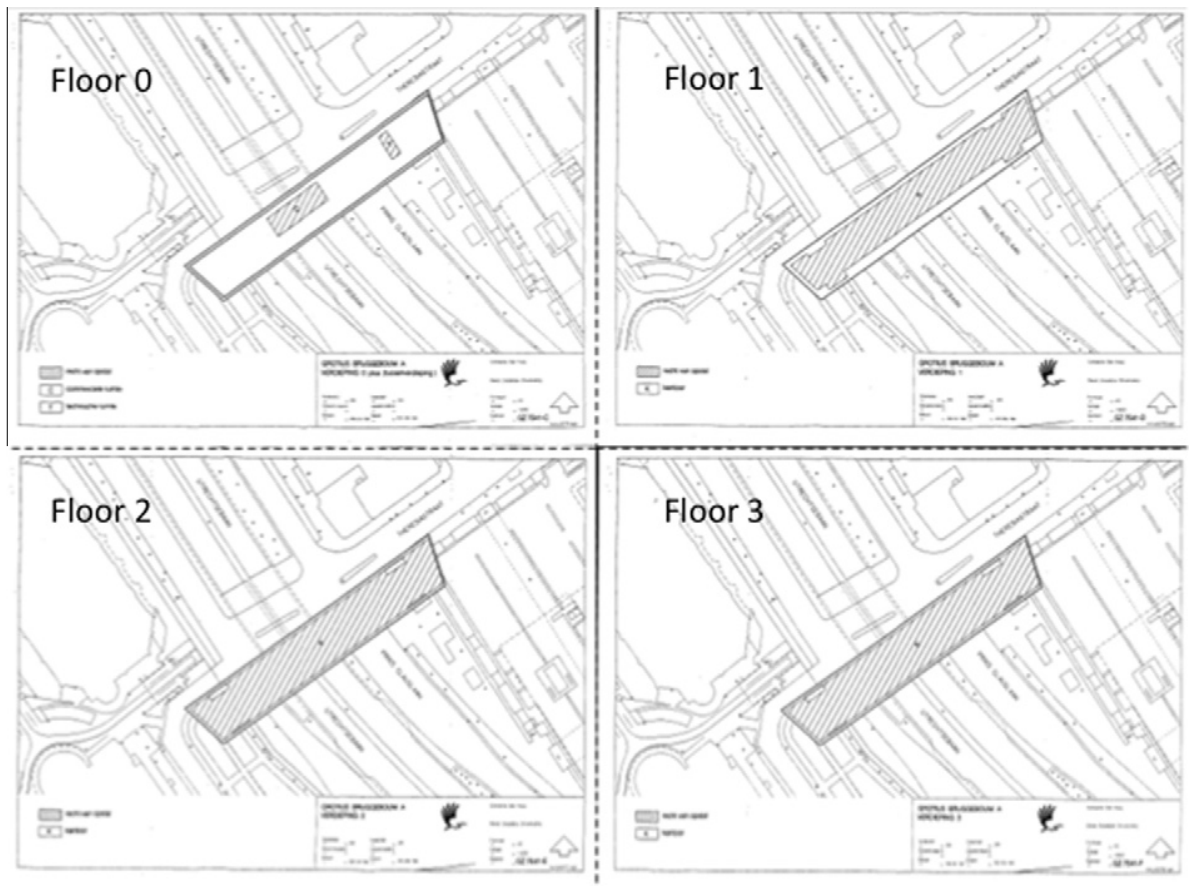

Fig. 7. Selection of drawings added to a deed that establishes a right of superficies for a building (covering approx. $300 \times 250 \mathrm{~m}$ ).

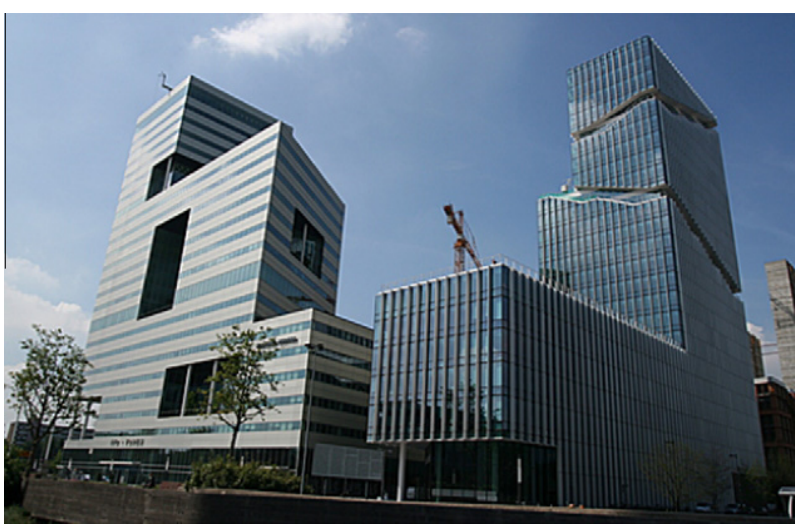

Fig. 8. Photograph of the real situation of case 2 (building on the right).

is made or that in the future one of the parcels is forgotten in a deed transferring the single real world object. Another disadvan- tage of these mini-parcels is that after subdivision of the original larger parcel all the rights, limitations and restrictions of the original parcel are copied to all the mini-parcels, while most likely those do not apply to all the mini-parcels. In most situations not the initial creation will cause problems, but the maintenance afterwards: updating the same legal fact attached to 80 mini-parcels after one real world change might be quite error prone.

\subsection{Case 3: building complex in Amsterdam, North}

The cadastral map in Fig. 10, above shows the complexity of registering property rights of objects on top of each other in a $2 \mathrm{D}$ parcel map. In this case several rights of superficies have been established for different 3D physical objects such as dam walls, parking ramps and spaces for technical equipment, needed during the construction phase of the building complex (Fig. 10). This resulted in the creation of several (very small) parcels because the $2 \mathrm{D}$ projections of the rights for the concerning objects overlap. In the system of the Dutch Cadastre Act the establishment of a 

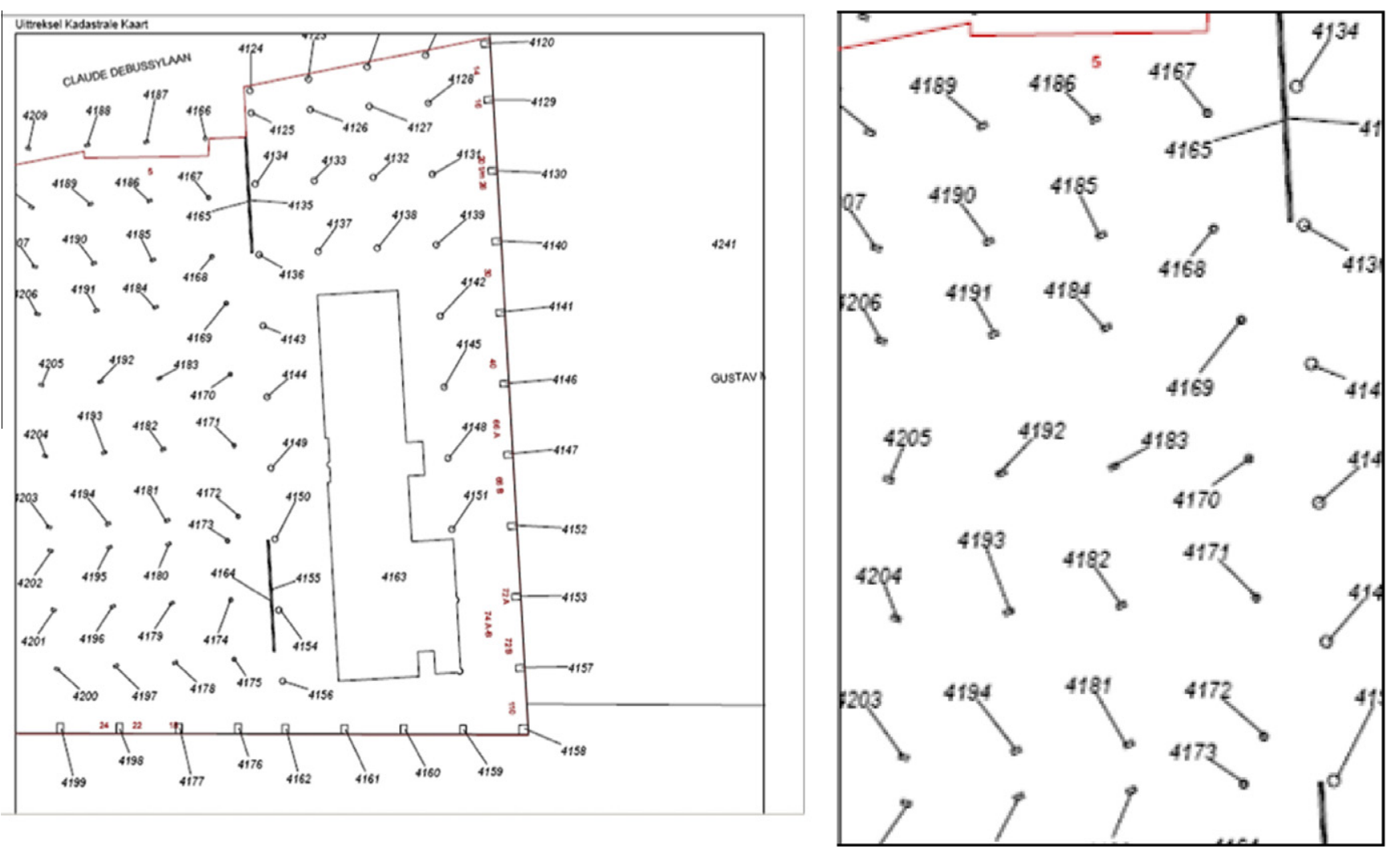

Fig. 9. Cadastral map (left, covering appr $250 \times 300 \mathrm{~m}$ ) showing the mini-parcels established for the foundation piles of the building in Fig. 8 .

property right on a part of a parcel will result in the subdivision of this parcel (explained in Section 3).

This specific case led to many questions regarding aligning the created parcels to the rights that have been established for the different physical objects. Because more than one right is established on the concerning parcels, it is not easy for the user to found out which parcel belongs to which object and consequently who is owner of what object.

\section{Proposed solution}

Conclusion from the case studies is that the registration and publication of rights on multi-level property is possible within the existing system of land registration in the Netherlands. However, the way it is currently done may require a mental exercise to understand the situation based on information available in the land and cadastral registers.

Apart from a better legal security in case of multi-level properties, the implementation of a 3D cadastre will also save costs. The measurement of each mini-parcel in the field, in situations as shown in case 2, costs 1000 euros per parcel. Consequently the registration of the building through 80 mini-parcels, cost 80,000 euros. This money can be saved when the building is registered through one 3D legal volume.

In this section we propose the optimal solution for 3D cadastre implementation. The solution is partly driven by the alternatives as studied in previous research (Section 2) and partly by the observation that implementing 3D cadastre in practice is a process that requires experience- and knowledge-building. Therefore the aim of the first phase (Section 5.2) is to gain experiences by introducing evolving technologies in the legal domain of 3D cadastre. The second phase (Section 5.3) aims at a more advanced 3D cadastre solution, which will accomplish a 3D cadastral registration at a fundamental level. Both phases do fit in the ISO FDIS 19152 Land Administration Domain Model (LADM; ISO/TC211, 2012; Lemmen et al., 2010) as explained in Section 2.

Both phases require common understanding of multi-level property situations that should be considered for 3D registration. Therefore firstly, Section 5.1 identifies the situations appropriate for a 3D approach.

\subsection{Situations that are defined as appropriate for $3 D$ registration}

The situations in which the spatial dimensions are relevant to be considered for $3 \mathrm{D}$ registration are the following:

(1) Multi-level property resulting from a building that is partly constructed on or in another's land. Based on the rule of "horizontal accession to real estate" as discussed in 3.1, the result of the construction over the parcels boundary is horizontal division of ownership. For the cadastral registration these situations are only relevant when a right has been registered that gives the right to have this part of the building above or under another property, i.e. right of superficies (as in Fig. 1) or easement.

(2) Complex, multi-level use rights registered with a right of superficies, long lease or easement that cannot be sufficiently represented in the $2 \mathrm{D}$ cadastral registration. The assurance of the legal status of these situations requires more 'visual' registration than is currently practised. The use rights could have been established either for physical constructions (case studies 1, 2 and 3), utility networks or "air parcels" (e.g. easements for ensuring free wind). Specific attention is paid for the "rights-in-right" situation, for example when the right of superficies is subdivided in space by using easements. 


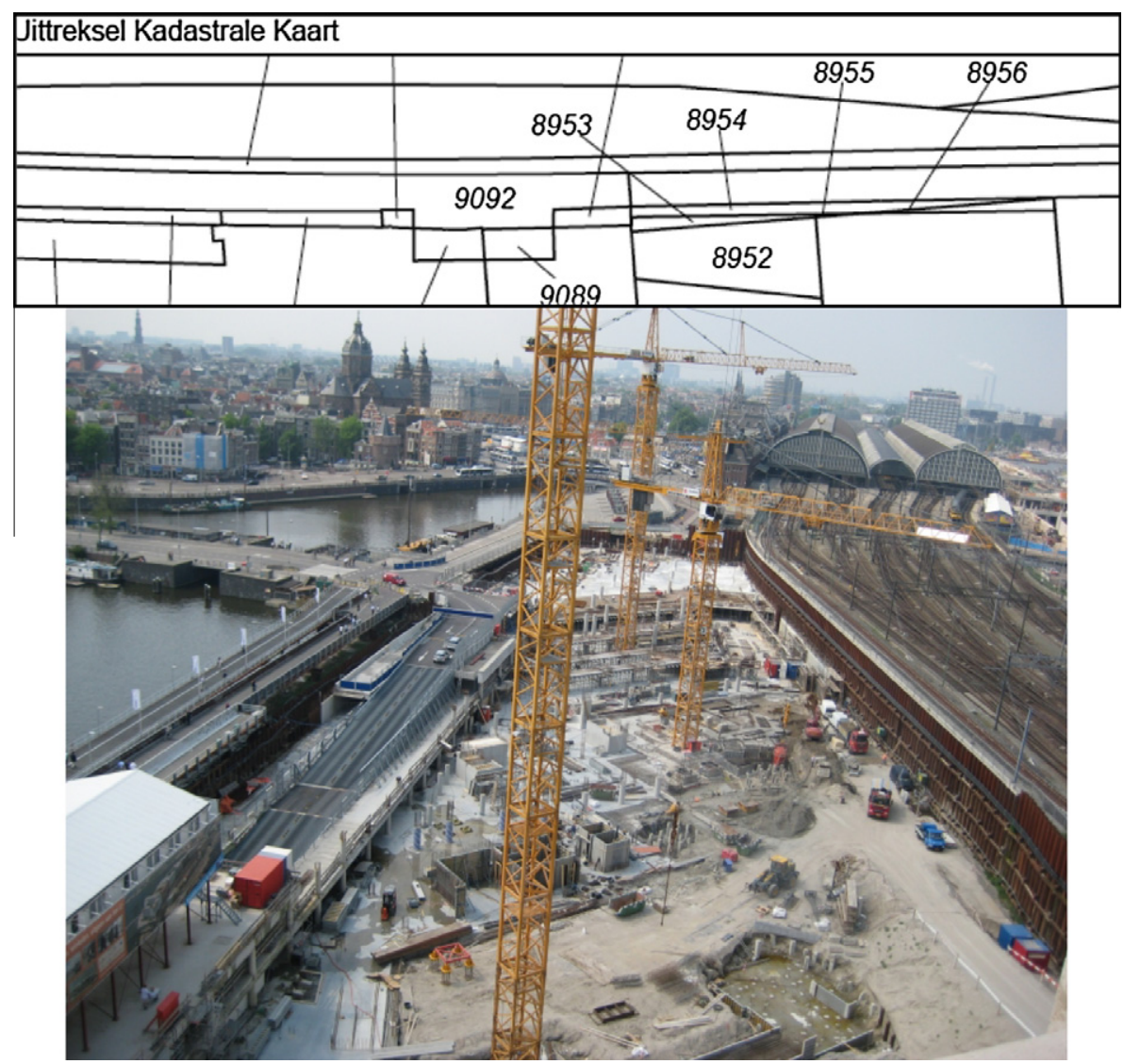

Fig. 10. Fragmented parcel pattern (area covers appr $10 \times 45 \mathrm{~m}$ ) established for several physical objects required in the construction phase of a building complex.

(3) Apartment complex that requires further specification in 3D: such as apartment units spread over several floors (e.g. apartment unit with the main part on the second floor, with a individual parking spot in the garage in the basement) and/ or apartment units that do not have the same $2 \mathrm{D}$ geometries for all floors and/or large building complexes. For example the apartment complex established on the foundation piles of case study 2, which becomes a complete coverage for the floors located above the surface. We distinguish apartment units as separate category, since they always handle about physical constructions and regulations for obliged drawings are already in force. In LADM terminology (ISO/ TC211, 2012), an apartment complex would correspond to a single LA_BAUnit consisting of multiple LA_SpatialUnits.

\subsection{First phase of $3 D$ cadastre implementation}

The first phase of 3D cadastre implementation exploits one of the LADM conceptual modelling options as introduced in Section 2 ; i.e. separate level with spatial units, which are associated with 3D drawing (LA_SpatialSource, playing the role of a sketch). The solution fits within current cadastral and legal frameworks and can therefore be implemented within a short time frame. In addition, the implementation will provide an empirical environment to gain experiences and support by all the stakeholders involved.

The implementation works as follows. In case of multi-level property, it is no longer allowed to subdivide a 2D parcel because of the projection of 3D objects in the cadastral map because this results in a unclear registration. Instead the original parcel will be maintained as cadastral object and for additional 3D cadastral objects a registrar requires a detailed 3D representation that provides insight into the property situations (established with either apartment right, right of long lease, right of easement or right of superficies). As mentioned earlier, such a $3 \mathrm{D}$ representation can be registered via a $3 \mathrm{D}$ drawing (in pdf format) within the ELAN system. A 3D pdf provides interaction and query possibilities that are very helpful in understanding 3D situations.

A notification is administrated on the parcel(s) on which a 3D representation is registered. The $2 \mathrm{D}$ projection of the $3 \mathrm{D}$ representation will be added for reference to the cadastral map by an extra graphics layer, like is done in Australia (Queensland Government, 2008; Stoter \& Van Oosterom, 2005) and Norway (Valstad, 2010).

Although current frameworks are used, the proposed 3D registration makes new use of those possibilities and therefore it is an innovation for cadastral registration in the Netherlands. In fact the major breakthrough is that the option to register a digital 3D drawing (possibly legally binding) will actually be practised. In addition, because the 3D drawing provides insight into the spatial dimensions of the right, new 2D parcels do not need to be created to delineate the exact boundaries of the 3D property on the ground parcel and creation of fragmented parcels can be avoided.

The (minimum) information required in the 3D representation to understand the multi-level property situation are identified as follows:

- 2D ground parcels that overlap (in projection) with the 3D legal volumes, draped over a Digital Terrain Model (to localise the parcels in space; e.g. is the legal space located above or below the earth surface). The overlap of the 3D space with the ground parcels should be identified (e.g. by hatching the specific area of the ground parcel).

- 3D (graphical) description of legal space. 
- To be in sync with the guidelines for drawings required for apartment units, the legally required 2D cross sections with accompanying annotations (e.g. unique identifier, north arrow, etc.). These cross-sections can be just another view on the same data, as will be shown in Fig. 11.

- Objects needed for reference and orientation in the 3D environment, i.e. at least the same as in current 2D cadastral map, which is 3D topography for reference purposes. The source for this could be the 3D topographic database, currently under construction at the Kadaster (Oude Elberink, Stoter, Ledoux, and Commandeur, accepted for publication).

- The 3D drawing should localise the 3D legal volume in both a local coordinate system and the national height datum system.

\subsubsection{Initial results}

It is important that the 3D registration does not bring a lot of extra costs. Therefore we investigated in collaboration with a design and construction company (VDNDP Bouwingenieurs), how the 3D drawings can be generated from existing digital design drawings (CADs) of the constructions. These types of companies are also the ones who currently prepare the map of divisions for apartment complexes.

Fig. 11 is the result of the foreseen workflow to generate 3D property drawings for an apartment complex. It shows several (cadastre-relevant) views (also cross-sections) on the same source data that was generated to construct the building.

From our experiences we can conclude that the costs to generate the $3 \mathrm{D}$ cadastre information in this format are similar to the costs involved for generating the currently obliged 2D maps of divisions in case of apartment complexes.

The outcomes of this hand-on study have been converted in a best practice procedure to support external parties to generate the information recommended for a 3D registration.

It should be noted that the described workflow focuses on newly built construction for which digital drawings are at hand.

\subsection{The second phase: $3 D$ registration for the long-term}

The disadvantage of the first phase-solution is that it focuses on visualisation. Therefore the 3D data is not available as such in the registration, which has several drawbacks. The data is necessary to check the validity of the $3 \mathrm{D}$ representation; e.g. is the space to which the right applies closed? Does it not overlap with spaces of other rights? In addition, if future transfers need to alter the 3D drawings, they cannot make use of the previous version of the data and they might need to collect the data again with risks of inconsistencies. Finally, data (and not just isolated 3D graphical illustrations) are needed to generate an overview that combines different 3D representations in a 3D overview; i.e. a true 3D cadastral map.

Techniques for 3D data acquisition, management and distribution are in reach. The next step is to optimally exploit these techniques to meet the more advanced implementation of a $3 \mathrm{D}$ cadastre. Therefore the planned solution of the second phase implements a full 3D cadastre alternative as described in Section 2 , i.e. combination of traditional, infinite parcel columns and volume parcels, defined by 3D data (e.g. polyhedrons) and not limited by 3D drawings.

The implementation requires a 3D geometrical representation in all cases identified as multi-level property situations (see Section 5.1).

How the Kadaster will accept the 3D data itself (which format) needs to be decided: (City)GML (OGC, 2012), or IFC (i.e. Industry Foundation Class; IFC, 2012) from the Building Information Model domain or ...? In first instance the Kadaster will not guarantee the $3 \mathrm{D}$ data, which is according to the deed registration in the Netherlands. In a future step Kadaster can decide to be responsible that the data correctly reflects the real situation like in a 'positive' system of title registration, as in Queensland (Queensland, 2008). In that case, the Kadaster should check the data on geometrical and topological correctness as well as on eventually overlap with other legal volumes. This is not trivial; see Thompson and van Oosterom

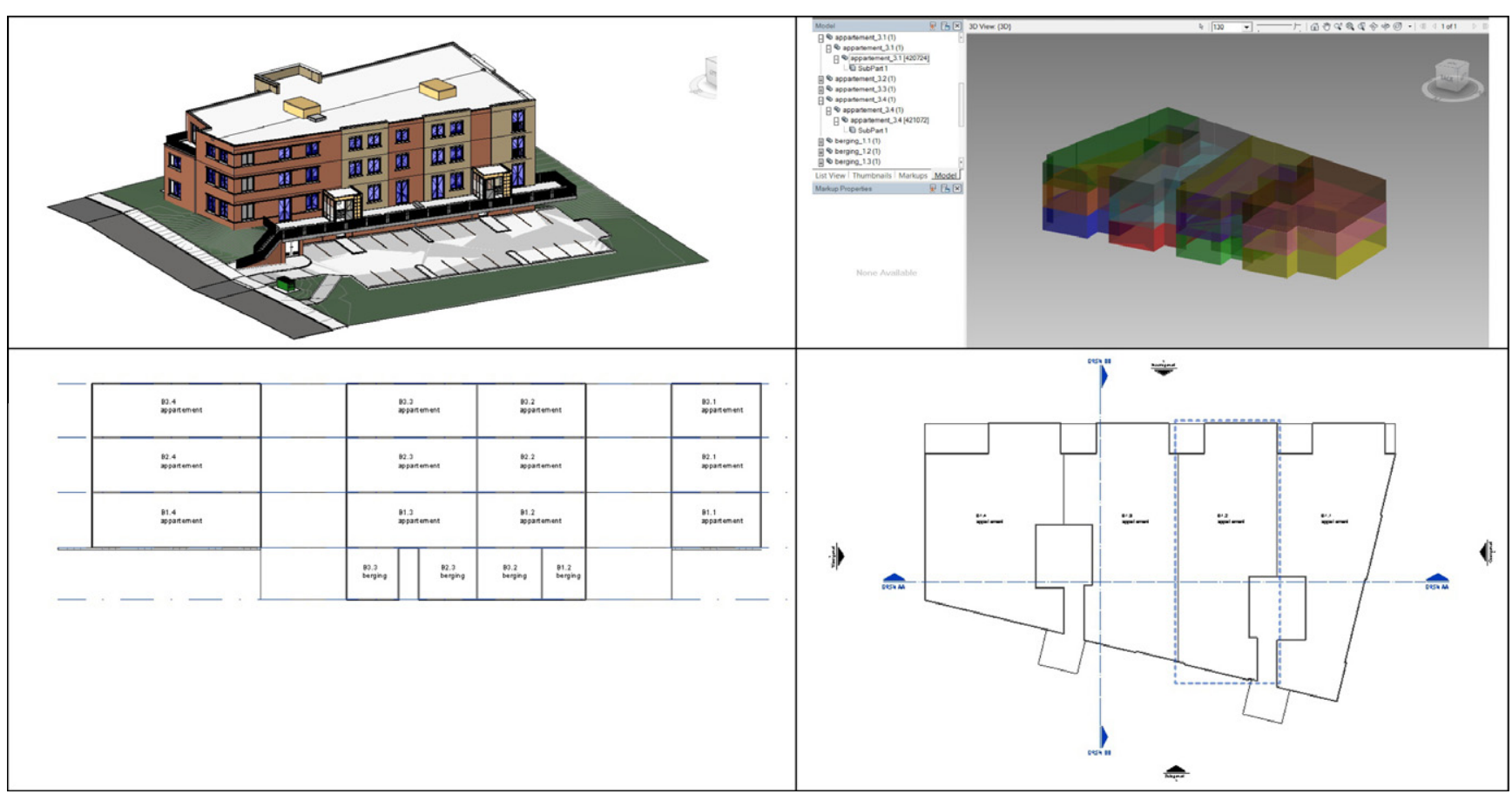

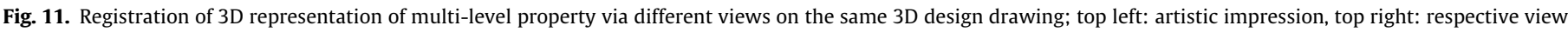
3D legal spaces, bottom left: vertical cross section, bottom right: floor plan of 1 ste floor. 
(2011). However such an option needs a fundamental shift in the current principles of land registration of the Netherlands.

The following principles further explain the implementation:

- The legal space is still related to one or more ground parcels (although one right of superficies can apply to several legal volumes within one parcel). The introduction of the possibility of free lying legal spaces would require a change in the Civil Code, which would take years. Therefore, when a 3D property does overlap with several ground parcels, for every ground parcel a specific right needs to be established. However this can be established in a single deed with one drawing, involving multiple surface parcels and a single volume corresponding to the 3D object. This volume gets an own identification. This is the only way to treat one real world object as a whole, even if it goes through several ground parcels.

- Apart from the format, also the allowed geometries need to be decided, i.e. fully enclosed by flat surfaces (polyhedron) or even by curved surfaces with precise mathematical descriptions of such as parts (e.g. cylindrical or spherical surface patches)? And is it allowed to have $3 \mathrm{D}$ representations that are open at the top (sky) or at the bottom (earth)?)

- The required precision relates to the value of the measures, i.e. also in 2D the reference to physical markers currently prevail above the boundaries in the cadastral map. However, having exact 3D information available as conversion of exact 3D drawings (or measured in the field by advanced tools) may question this rule in the Netherlands and opt for a different approach. To add measures to constructions, it is preferable to follow the national standard on measuring volumes and areas within constructions (NEN 2580, 2007). This standard is used in the building and construction domain.

The optimal implementation will be further shaped, also by experiences gained during the first phase and an analysis of ongoing developments in other countries (Olivares García, Virgós Soriano, \& Velasco Martín-Varés, 2011; Queensland Government, 2008; Valstad, 2010; Vandysheva et al., 2011).

\section{Conclusions}

This paper presents the 3D cadastre developments in the Netherlands and proposes an actual implementation of a 3D registration of multi-level property fitting within the international standards of the ISO 191xx family (and more specifically ISO FDIS 19152, Land Administration Domain Model; LADM). The proposed solution builds on alternatives proposed in earlier research and consists of two phases. The first phase (for the short term) fits within the current cadastral and legal frameworks and the second phase focuses on a long-term solution that also facilitates to register 3D geometrical data apart from a 3D drawing. Both phases target an appropriate registration of $3 \mathrm{D}$ rights and restrictions. Making this 3D information accessible via a (direct) link in the cadastral map is part of the solution (phase one). However the registration of 3D data is under study for phase two.

This paper proposes a solution for 3D registration within a given legislation and therefore a national setting. However the needs to develop the current system land registration towards an efficient and clear representation of complex property situation that occur as a result of intensified land use and multiple use of space is certainly not limited to the Netherlands. Other countries face similar limitations of legislation and/or cadastral regulations to facilitate appropriate 3D registrations, as can be concluded from the international comparison carried out by the FIG joint commissions 3 and 7 working group on 3D-cadastres (van Oosterom et al., 2011). As the presented solution is based on international standards, similar approaches can be applied in other countries; e.g. as illustrated with the 3D cadastre prototype in the Russian Federation (Vandysheva et al., 2011).

The approach for phase one (making 3D registration works within the actual legal and cadastral frameworks) will fit within many jurisdictions. The developments in the Netherlands as described in this paper will therefore contribute to further study and subsequent development in other countries. However it does not provide a "manual" for implementation that can be followed anywhere in the world. The actual implementation of a 3D registration will always depend on the characteristics of the current land law and system of land registration in a certain jurisdiction.

Future work will refine the goals for the second phase of the implementation of 3D registration, which will encounter a more significant change with respect to current registration because it will also cover the steps after the submission of a 3D geometrical representation: how will this be managed in the cadastral database(s), how can users (within and outside the Kadaster) access this 3D information? Handling this kind of rich 3D information is much more complicated than storing 3D pdf's and make these available after selection in the 2D cadastral map and requires therefore further research.

\section{Acknowledgements}

We are grateful to the anonymous CEUS reviewers, who helped us to improve the manuscript. We would also like to thank the LADM development team for the pleasant cooperation, and more in specific João Paulo Hespanha, Chrit Lemmen, Rod Thompson, and Harry Uitermark. This research is supported by the Dutch Technology Foundation STW, which is part of the Netherlands Organisation for Scientific Research (NWO) and partly funded by the Ministry of Economic Affairs, Agriculture and Innovation (Project codes: 11300 and 11185 .

\section{References}

Adobe (2012). 3D pdf technology. <http://www.adobe.com/manufacturing/ solutions/3d_solutions/> Accessed 29.02.12.

Aien, A., Rajabifard, A., Kalantari, M., \& Williamson, I. (2011). Aspects of 3D Cadastre - A case study in Victoria. In Proceedings FIG working week 2011 (15 p.), Marrakech.

Benhamu, M., \& Doytsher, Y. (2003). Toward a spatial 3D cadastre in Israel. Computers, Environment and Urban Systems, 27, 359-374.

Döner, F., Thompson, R., Stoter, J. E., Lemmen, C. H. J., Ploeger, H. D., van Oosterom, P. J. M., et al. (2010). 4D cadastres: First analysis of Legal, organizational, and technical impact - With a case study on utility networks. Land Use Policy, 27, 1068-1081.

Döner, F., Thompson, R., Stoter, J. E., Lemmen, C. H. J., Ploeger, H. D., van Oosterom, P. J. M., et al. (2011). Solutions for 4D cadastre - With a case study on utility networks. International Journal of Geographical Information Science, 25(7), 1173-1189.

Eriksson, G., \& Jansson, L. (2010). Strata Titles Are Introduced in Sweden. In Proceedings XXIV international FIG congress (13 p.), Sydney.

Guo, R., Ying, S., Li, L., Luo, P., \& Van Oosterom, P. (2011). A multi-jurisdiction case study of 3D cadastre in Shenzhen, China as experiment using the LADM. In Proceedings 2 nd international workshop on 3D cadastres (pp. 31-50), Delft.

IFC (2012). Industry foundation classes release $2 \times 4$ (IFC4) release candidate 3 specification. <http://buildingsmart-tech.org/ifc/IFC2x4/rc3/html/index.htm>.

ISO/TC211 (2012). ISO/TC 211 geographic information - Land Administration Domain Model (LADM). ISO/FDIS 19152 (final draft international standard).

Kadaster (2007). European eGovernment Awards 2007, submission case ELAN, effective and efficient administration: Electronic Conveyancing. <http://www.kadaster.nl/ pdf/Case_elan_engels.pdf $>$.

Karki, S., McDougall, K., \& Thompson R. (2010). An overview of 3D cadastre from a physical land parcel and a legal property object perspective. In Proceedings XXIV international FIG congress (13 p.), Sydney.

Kaufmann, J., \& Steudler, D. (1998). Cadastre 2014 report of commission 7 working group 7.1, modern cadastres, FIG, Commission 7, Tech. Rep (8 p.). <http:// www.fig.net/cadastre2014/presentation/1998-07-kaufmannsteudler-brightoncad2014-paper.pdf>. 
ARTICLE IN PRESS

12

J. Stover et al./Computers, Environment and Urban Systems $x x x$ (2012) $x x x-x x x$

Lemmen, C., van Oosterom, P., Uitermark, H., Thompson, R., \& Hespanha, J.P. (2009). Transforming the Land Administration Domain Model (LADM) into an ISO standard (ISO19152). FIG working week 2009. Eilat, Israel. <http:// www.gdmc.nl/publications/2009/LADM_to_ISO_Standard.pdf>.

Lemmen, C., van Oosterom, P., Thompson, R., Hespanha, J.P., \& Uitermark, H. (2010). The modelling of spatial units (Parcels) in the Land Administration Domain Model (LADM). In XXIV international FIG congress (28 p.), Sydney.

NAN 2580 (2007). Oppervlakten en inhouden van gebouwen - Termed, definities en bepalingsmethoden. $\quad<$ http://www.nen.nl/web/Normshop/Norm/NEN25802007-nl.htm?gclid=CMy5rrS-qrACFcZJ3god_3shWA>.

OGC (2012). OpenGIS ${ }^{\circledast}$ City Geography Markup Language (CityGML) Encoding Standard, version 2.0. <http://www.opengeospatial.org/standards/citygml>.

Olivares García, J. M., Virgós Soriano, L. I., \& Velasco Martín-Varés, A. (2011). 3D modeling and representation of the Spanish Cadastral cartography. In Proceedings of the Ind international workshop on 3D cadastres (pp. 209-222), Delft. <http://3dcadastres2011.nl/documents/013.pdf>.

Onsrud, H. (2003). Making a cadastre law for 3D properties in Norway. Computers Environment and Urban Systems, 27, 375-382.

Dude Elberink, S., Stater, J. E., Ledoux, H., \& Commander, T. (accepted for publication). Generation and dissemination of a National Virtual 3D City and Landscape Model for the Netherlands. Journal on Photogrammetric Engineering \& Remote Sensing (PEERS).

Paulsson, J. (2007). 3D property rights - An analysis of key factors based on international experience. PhD Thesis, Royal Institute of Technology (KTH), Stockholm, $351 \mathrm{p}$.

Pouliot, J., Roy, T., Fouquet-Asselin, G., \& Desgroseilliers, J. (2010). 3D cadastre in the province of Quebec: A first experiment for the construction of a volumetric representation. In Proceedings 5th international 3D GeoInfo conference (15 p.), Berlin.

Queensland Government (2008). Department of Environment and Resource Management. Registrar of titles directions for the preparation of plans, 19 May 2008.<http://www.derm.qld.gov.au/property/titles/rdpp/pdf/regdir37.pdf>.
Rahman, A. A., Hua, T. C., \& Van Oosterom, P. (2011). Embedding 3D into multipurpose cadastre. In Proceedings FIG working week (20 p.), Marrakech.

Stater, J. (2004). 3D cadastre. PhD thesis TU Delft, Publications on Geodesy 57, Netherlands Geodetic Commission, Delft, 327 p.

Stater, J. E., \& Ploeger, H. D. (2003). Property in 3D-registration of multiple use of space: current practice in Holland and the need for a 3D cadastre. Computers, Environment and Urban Systems (CEUS), 27, 553-570.

Stater, J. E., \& Salzmann, M. E. (2003). Where do cadastral needs and technical possibilities meet? In P.J.M. van Oosterom and C.H.J. Lemmen (Eds.), Cadastral systems III, 3D cadastre. Computers, Environment and Urban Systems (CEUS), July 2003 (Vol. 27, pp. 395-410). ISSN: 0198-9715.

Stater, J. E., \& Van Oosterom, P. J. M. (2006). 3D cadastre in an international context: Legal, organizational and technological aspects. Taylor \& Francis (323 p.). ISBN 08493-3932-4.

Stater, J. E., \& Van Oosterom, P. J. M. (2005). Technological aspects of a full 3D cadastral registration. International Journal of Geographical Information Science, 19(6), 669-696.

Thompson, R., \& van Oosterom, P. (2011). Axiomatic definition of valid 3D parcels, potentially in a space partition. In Proceedings of the 2 nd international workshop on 3D cadastres (pp. 397-416), Delft. <http://3dcadastres2011.nl/documents/ 023.pdf $>$.

Valstad, T. (2010). After 10 years in waiting Norway has a New Cadastral Law that also includes 3D objects. <http://www.fig.net/pub/fig2010/ppt/ts05a/ts05a valstad_ppt_4473.pdf>.

Van Oosterom, P., Stoter, J., Ploeger, H., Thompson, R., \& Karki, S. (2011). World-wide Inventory of the Status of 3D cadastres in 2010 and Expectations for 2014. FIG working week 2011, Marrakech, 21 p. <http://www.fig.net/pub/ monthly_articles/may_2011/may_2011_vanoosterom_stoter_et_al.pdf>.

Vandysheva, N., Ivanov, A., Pakhomov, S., Spiering, B., Stover, J., Zlatanova, S., \& Van Oosterom, P. (2011). Design of the 3D cadastre model and development of the prototype in the Russian Federation. In Proceedings of the ind international workshop on 3D cadastres (pp. 355-375), Delft.

Please cite this article in press as: Stover, J., et al. 3D cadastre in the Netherlands: Developments and international applicability. Computers, Environment

and Urban Systems (2012), http://dx.doi.org/10.1016/j.compenvurbsys.2012.08.008 